\title{
A Smart Market for Ground and Surface Water with Hydropower Generation
}

Rebecca Teasley ${ }^{1}$, John Raffensperger ${ }^{2}$, and Mark Milke ${ }^{3}$

${ }^{1}$ Department of Civil and Natural Resources Engineering, University of Canterbury, Private Bag 4800, Christchurch 8140, New Zealand; PH +64 (3) 364-2987; FAX +64 (3) 364-2758; email: rebecca.teasley@canterbury.ac.nz

${ }^{2}$ Department of Management, University of Canterbury, Christchurch, NZ University of Canterbury, Private Bag 4800, Christchurch 8140, New Zealand; PH +64 (3) 364-2248; FAX +64 (3) 364-2020; email: john.raffensperger@canterbury.ac.nz ${ }^{1}$ Department of Civil and Natural Resources Engineering, University of Canterbury, Private Bag 4800, Christchurch 8140, New Zealand; PH +64 (3) 364-2248; FAX +64 (3) 364-2758; email: mark.milke@canterbury.ac.nz

\begin{abstract}
Communities and government world-wide have growing concern over the protection of groundwater resources. We have been studying smart markets as a tool to efficiently allocate groundwater, to protect against groundwater depletion, and to prevent damage to environmentally sensitive areas. In this paper, a smart market is proposed for the combination of ground water and surface water, which includes bids for reservoir releases by a hydropower generator. The smart market here is a periodic auction which uses an optimization model to allocate water. The optimization model includes physical constraints based on the aquifer, surface water availability as calculated in a simulation model, and user bids. The simulation model calculates characteristics of an aquifer such as water availability and the interaction under various pumping regimes with surface water, as water is released for hydropower generation. In addition to the physical constraints provided from the simulation model, the optimization model is constrained by each user's demand for water. A piece-wise linear demand function relates each user's willingness to pay for incremental volumes of water. Under the market, users can use their water right, or sell some or all of it to the central pool, or buy additional water. Prices are determined by the exchange of water rights in a bidding system, as in an auction. The bidding system is based on each user's demand curve, which relates additional volumes of water to prices that they are willing to pay for that additional volume of water.
\end{abstract}

\section{Introduction}

Communities and governments world-wide have growing concern over the protection of groundwater resources. Major issues associated with groundwater protection are how to efficiently allocate groundwater, how to prevent groundwater depletion, and how to prevent damage to the environment. A key difficulty in managing groundwater is the inability to reallocate water between users easily, due to the large transaction costs from searching for trading partners, writing contracts, and obtaining government permissions. Considering the potential interaction of groundwater with surface water adds complexity to the water management issues. One tool being examined to overcome these management difficulties are water markets.

Operational water markets have been developed for some surface water systems around the world (Griffin and Characklis 2002; Bjornlund, 2003; Cai et al., 2003). These markets often 
have high transaction costs, as is indicated by the relative infrequency of trade and the large size of the trades. Markets are also in operation for groundwater. An interesting example is that of the commercial website www.hydrotrader.co.nz, which seeks to match buyers and sellers of groundwater in the province of Canterbury, NZ. Despite actively seeking traders, the firm completed only fifteen trades between November 2007 and January 2010. Every trade was for at least a year, implying large transaction costs. The essential problem is that a common resource is being traded pair-wise, hence government approval is required for every trade, creating the large transaction costs and increasing the time requirements to make that trade.

For other commodities, such as electricity, natural gas, and radio spectrum, business and governments are actively using smart markets to trade these complex resources. Smart markets are computer aided auctions which use optimization models to maximize user benefit within set constraints such infrastructure capacity, and user bids, making this type of market suitable for shared complex resources. Ownership of electricity, for example, cannot be tracked across a shared network and generation and demand must be balanced in real time. These complexities lend themselves well to optimization, and the optimization model's constraints ensure that transmission stays within line capacities, and that generation equals demand. To turn such an optimization into a market, the operator uses generators' and demanders' bids in the optimization objective function. Rather than trade pair-wise, all trades are made from a common pool of bids. The market does not create bilateral trades between individual market participants (Raffensperger et al., 2010), but rather clears all bids and offers simultaneously. Hence, the transaction cost falls nearly to zero, and trades can be made in near real time.

This research extends the work on groundwater smart markets by Raffensperger and Milke (2005), further developed and applied to a basin in Marlborough, New Zealand, by Raffensperger et al. (2009). The smart market for groundwater allocates water to maximize user benefit within constraints on water availability, infrastructure capacity, protection standards for the environment, and users' bids. That research is extended here to include groundwater and surface water interaction, and, in particular, reservoir releases for hydropower generation.

\section{Market Control}

In a groundwater market, no user is likely to monopolize the resource by bidding up prices, because of the large number of participants and the dispersed nature of groundwater. Typically, a well owner has the most control of water locally, and less control of water further away and any user who somehow obtained control of the dispersed groundwater would also need control of sufficient land to employ the water productively.

In a combined ground and surface water market, however, the reservoir operator (RO) could plausibly have significant market power, due to control of the reservoir releases. For example, the RO could hold water until downstream constraints come into effect, increasing prices. Releasing water into a high-demand market may raise the hydrogenerator's profit, while lowering the benefit for downstream agricultural users. The smaller the impact of surface water fluctuations on groundwater levels, the less a groundwater user would be concerned by this potential for market control. Similarly, water users upstream of a hydropower reservoir could exert market control over the hydropower users. Complicating this is the RO's desire to hold water for future periods, when power prices may be higher, as well as the farmers' desire for certainty of supply in future periods.

A major question is when would market control become significant? The RO has minimum and maximum reservoir capacity constraints, which may limit market power at 
extremes. Further, the RO may be more concerned with generation into the power market, which usually operates on a half-hourly basis, and which may be a much larger revenue source. In that case, the RO would have little concern with the water market. These issues related to market control under surface water and groundwater interactions remain to be investigated. Tis paper presents the market design for a surface and groundwater system with a simple case study.

\section{Smart Market Formulation}

The smart market design for the example in this paper uses a linear program (LP) to allocate water. The objective of the LP is to maximize user benefit, based on users' bids and demand curves. The LP constraints ensure that groundwater levels are not drawn down too far, and that the surface water flow does not fall below a minimum standard set at the control points. Under the market, users may have existing quota for water, which they can use or sell to other users based on current market prices. Users can also offer to buy additional quota. Before each auction, the auction manager invites each user to submit a bid package made of multiple parts, or tranches. Each tranche represents the price of an increment (marginal quantity) of water at which a user is willing to buy or sell. These tranches correspond to a piece-wise linear approximation of the user's demand function, which is the user's willingness to pay for incremental volumes of water. Each tranche has a price and a quantity and the LP includes a constraint for each tranche, for each user, in each time period.

Physical constraints of the aquifer are developed with the help of GWM (Ahlfeld et al., 2005) and MODFLOW-2000. MODFLOW-2000 simulates the aquifer including its spatial and physical characteristics such as hydraulic conductivity, recharge and well locations. GWM can create a response matrix $F_{w k}^{t}$, which describes the physical relationship between aquifer heads (at control points) and the pumping wells over time. The response matrix is assumed to be linear (Greenwald, 1998; Ahlfeld et al., 2005; Pulido-Valazquez et al., 2006). The response matrix then becomes coefficients in the LP. Upper and lower bounds on control points and minimum flows in surface water are usually set by an environmental authority, and may be used to ensure sufficient water in wetlands, prevention of coastal salt water intrusion, etc.

\section{Linear Program}

The linear program is modified from the groundwater smart market model developed by Raffensperger et al. (2009) and includes reservoir releases. The LP is developed as follows:

\section{Indices}

$b \quad=\quad$ demand tranches.

$w \quad=\quad$ users, $w=0, \ldots, W$. User 0 is the RO. Users $1, \ldots W$ are well owners.

$k, l=$ control points.

$D \quad=\quad$ set of control points $(k, l)$ between which head difference is constrained.

$u, t \quad=\quad$ time period.

\section{Parameters}

$Q_{w b}^{t} \quad=\quad$ withdrawal limit on demand tranche $b$ at well $w$ in period $t$. 
$P_{w b}^{t} \quad=\quad$ bid price for demand quantity $Q_{w b}^{t}$ at well $w$ in period $t$.

$F_{w k}^{t} \quad=\quad$ head drawdown rate in period $t$ at control point $k$ due to withdrawal at well $w$ in period 1.

$G_{k}^{t} \quad=\quad$ rate of head increase at control point $k$ due to unit release from the reservoir in the current period $t$. This depends on the river bed conductivity.

$L_{k}^{t} \quad=\quad$ lower bound on head at control point $k$ in period $t$.

$U_{k}^{t} \quad=\quad$ upper bound on head at control point $k$ in period $t$.

$N_{k}^{t}=$ initial head at control point $k$ in period $t$.

$L D_{k, l}^{t} \quad=\quad$ lower bound on the head difference between control points $k$ and $l$ in period $t$ with the head at $k$ larger than the head at $l$.

$U D_{k, l}^{t} \quad=\quad$ upper bound on the head difference between at control points $k$ and $l$ in period $t$.

\section{Decision Variables}

drawdown $n_{k}^{t} \quad=$ cumulative drawdown at control point $k$ after $t$ periods.

$p_{w}^{t} \quad=\quad$ market price per unit of water at well $w$ in period $t$.

$q_{w b}^{t}=\quad$ withdrawal volume at price $P_{w b}^{t}$ accepted for the user at well $w$ in period $t$.

$q_{w}^{t} \quad=\quad$ total withdrawal volume from well $w$ during period $t$.

$r^{t}, r_{b}^{t}=$ total reservoir release at period $t$, and reservoir release at period $t$ with bid $b$.

\section{Linear Model}

1. Maximize $\sum_{w=1}^{W} \sum_{t=1}^{T} \sum_{b=1}^{B} P_{w, b}^{t} q_{w, b}^{t}+\sum_{t=1}^{T} \sum_{b=1}^{B} P_{b}^{t} r_{b}^{t}$, subject to:

2. $0 \leq q_{w, b}^{t} \leq Q_{w, b}^{t}$ each user $w$, for each tranche $b$, for each time period $t$.

3. $q_{w}^{t}=\sum_{b=1}^{B} q_{w, b}^{t}$ for each user $w$ and for each time period $t$. Dual price $p^{t}{ }_{w}$.

4. $r_{\min } \leq r_{b}^{t} \leq R_{b}^{t}$ for tranche $b$ in time period $t$.

5. $r^{t}=\sum_{b}^{B} r_{b}^{t}$ for each demand tranche $b$ in each period $t$. Dual price $p_{r}^{t}$.

6. drawdown $n_{k}^{t}=\sum_{w=1}^{W} \sum_{u=1}^{t} F_{w, k}^{t-u+1} q_{w}^{u}-\sum_{u=1}^{t} G_{k}^{t-u+1} r^{t}$, for all control points $k$, and time periods $t$.

7. $L_{k}^{t} \leq N_{k}^{t}-d r a w d o w n_{k}^{t} \leq U_{k}^{t}$, for all control points $k$, and time periods $t$.

8. $L D_{k l}^{t} \leq\left(N_{k}^{t}-\right.$ drawdown $\left._{k}^{t}\right)-\left(N_{l}^{t}-\right.$ drawdown $\left._{l}^{t}\right) \leq U D_{k l}^{t}$

\section{Description of Model}

1. The objective maximizes the total value of water to participants. 
2. Withdrawal volume $q_{w b}^{t}$ for each user $w$, for each tranche $b$, is bound for each period $t$.

3. Withdrawal $q_{w}{ }^{t}$ by each user $w$, for each period $t$, equals the total accepted bid. The dual price $p^{t}{ }_{w}$ is the price which will be used to charge or pay user $w$ for quota to be taken in period $t$.

4. Release $r^{t}$ from the reservoir for each tranche $b$ is bound for each period $t$.

5. Release $r^{t}$ from the reservoir, for each period $t$, equals the total accepted bid.

6. Drawdown at control point $k$ in period $t$ is a weighted sum of previous abstractions by all wells, $w$.

7. Upper and lower bounds on head at control points ensure that environmental and regulatory limits are satisfied.

8. Head differences between control points are constrained to ensure that groundwater flow occurs in a certain direction. These constraints can also provide a limit on the rate of groundwater flow.

\section{Market operation}

In the proposed smart market, the auction manager is responsible for obtaining the relevant data to construct the market LP. The auction manager would run MODFLOW-2000 and GWM to obtain the response matrix coefficients, and would set the control point upper and lower bounds from existing regional laws or regulations. The auction manager then seeks bids from users, which could be input by the users via a web page. Before each auction, each user has some initial level of quota $C^{t}{ }_{w}$ whether obtained from previous permanent purchases, or from previous leases, net of all trades. A user $w$ cannot offer to sell more quota for time period $t$ than their initial quota $C_{w}^{t}$. Each user in the market decides how to bid independently and then enters those bids into the auction.

The market is cleared at an appointed interval, such as weekly, depending on the characteristics of the system. At the appointed time, the auction manager closes bidding for the current auction, constructs and solves the LP, and reports the results back to users. Each user is then paid $p^{t}{ }_{w}\left(C^{t}{ }_{w}-q^{t}{ }_{w}\right)$. Because $p^{t}{ }_{w} \leq 0$, this net charge will be a charge if $C^{t}{ }_{w}<q^{t}{ }_{w}$. Each user $w$ then has a firm right to take $q_{w}^{t}$ units of water during time period $t$. An important note is that each auction can trade quota for future periods.

\section{Example}

The smart market approach is illustrated with a simple transient groundwater model, set up in MODFLOW-2000. This example is modified from an example problem presented by Ahlfeld, et al. (2005), to include reservoir releases into the stream. This example is a single layer, unconfined aquifer with four pumping wells (Users A, B, C and D), a stream with reservoir releases and one tributary (Figure 1). To ensure inclusion of reservoir releases into the response matrix as a decision variable, releases are modeled as a single pumping well that injects water into the stream bed. The problem has 4 control points (CP 1, 2, 3, 4) in specified segments of the stream and its tributary, where the auction manager has specified minimum stream flows.

The model includes eight stress periods with 7 daily time steps. To ensure that control points are not violated beyond the end of the model horizon, irrigators are allowed to bid for water only for the next six stress periods, with a rolling horizon. Users $A$ and $B$ have initial rights to take $C_{a}{ }^{t}=C_{b}{ }^{t}=50,000 \mathrm{~m}^{3} /$ period, and users $C$ and $D$ have initial rights to take $C_{c}{ }^{t}=C_{d}{ }^{t}$ $=1,000 \mathrm{~m}^{3} /$ period, for periods $t=1, \ldots, 6$. The RO has no obligation to release water, but is 
incentivized to release some amount due to the value of the releases in the electricity market. The $\mathrm{RO}$ will be paid for any release; however it is important to note that this need not be the case. In some river basins, the RO may be responsible for ensuring that environmental flows are satisfied, and in those basins, the RO may buy water from farmers to ensure that those environmental constraints are satisfied.

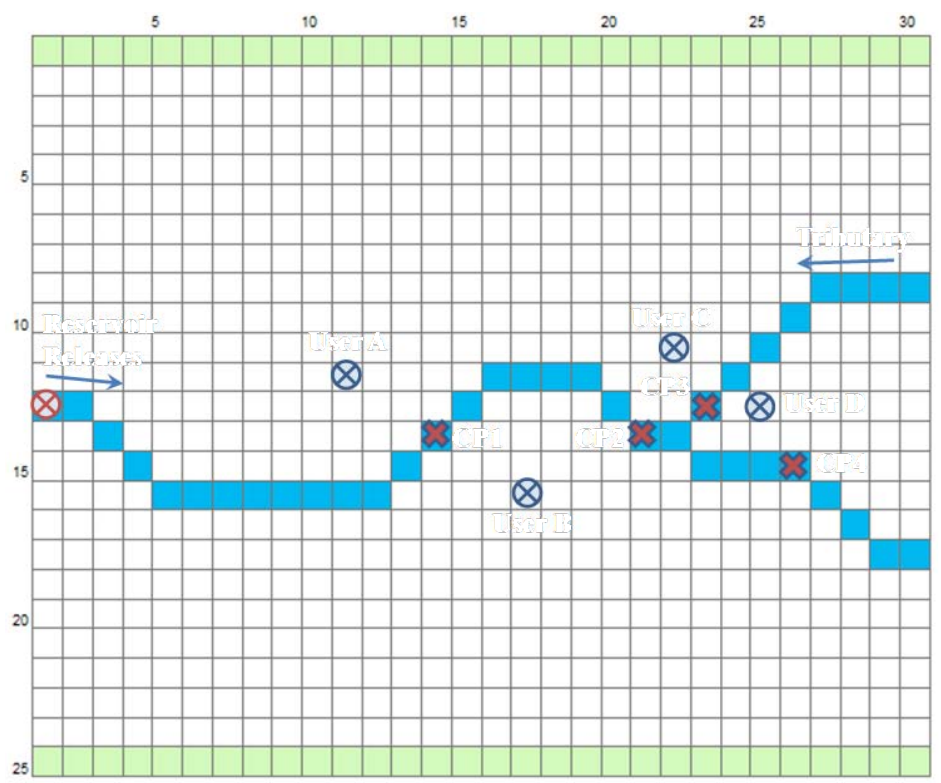

Figure 1 Grid of the groundwater system as modeled in MODFLOW-2000, adapted from Ahlfeld, et al. (2005).

Two cases are presented that differ in the RO's bids. In both cases, the irrigators bid identically per unit of water, in every period. Despite the identical bids, it will be shown that prices at locations differ because the hydrology is not uniform across the catchment. In Case 1, the $\mathrm{RO}$ is willing to release a relatively large amount of water, while in Case 2 the RO reduces releases to try to raise prices.

For wells, the bid tranches are constructed as five pairs of volume (in cubic meters) and price (in dollars); (8,333, \$0.05), (16,667, \$0.04), (25,000, \$0.03), (50,000, \$0.02), (100,000, $\$ 0.01)$. These tranches imply that each user has the most value for the first 8,333 cubic meters of water, $\$ 0.05 /$ unit. Subsequent marginal quantities are less valuable, up to the last marginal quantity of 100,000 cubic meters, which is worth only $\$ 0.01 / \mathrm{m}^{3}$. Because these are marginal quantities, the maximum quantity of water that each well would take is the sum of the tranche quantities, 200,000 $\mathrm{m}^{3}$.

The RO's bids are constructed similarly as five pairs, (16,667, \$0.02), (33,333, \$0.01), (50,000, \$0), (100,000,-\$0.005), (200,000,-\$0.01). The negative dollar values imply that future periods have higher value of water to the RO. Thus, a large release would cost the RO future earnings, if future periods were expected to be dry but have high demand for electricity. 


\section{Case 1. Identical Bids}

In the solution, the objective function value was $\$ 31,796$, the total value of the water allocated. Payments are calculated as $\sum_{t} p^{t}{ }_{w}\left(C_{i}{ }^{t}-q_{w}^{t}\right)$ for each farmer $w$, and $p_{r}^{t} r^{t}$ for the RO. Binding control point constraints were present for Control Point 3 in periods 1 through 6 , and at Control Point 4 in period 1. The full solution for Case 1 is shown in Table 1. An important point is that no party trades pair-wise. Instead, farmers and the RO deal with the auction manager, who receives payments when a user buys, and disburses money when a user sells. All of the trades are made through the central pool; this nearly eliminates the transaction costs associated with operating the market.

Table 1. Solution to Case 1 . The $\mathrm{RO}$ also releases $50,000 \mathrm{~m}^{3}$ in periods 7 and 8 .

\begin{tabular}{|c|c|c|c|c|c|c|c|}
\hline & User & Period 1 & Period 2 & Period 3 & Period 4 & Period 5 & Period 6 \\
\hline \multirow{5}{*}{$\begin{array}{c}\text { Quantity, } \\
\mathrm{m}^{3}\end{array}$} & $A$ & 100,000 & 100,000 & 100,000 & 68,411 & 100,000 & 100,000 \\
\hline & $B$ & 100,000 & 50,000 & 50,000 & 50,000 & 50,000 & 50,000 \\
\hline & $C$ & 0 & 0 & 0 & 0 & 0 & 0 \\
\hline & $D$ & 1,517 & 0 & 0 & 0 & 0 & 0 \\
\hline & $\mathrm{RO}$ & 117,578 & 132,346 & 192,488 & 179,088 & 174,795 & 200,000 \\
\hline \multirow{5}{*}{ Price, \$ } & $A$ & $\$ 0.018$ & $\$ 0.019$ & $\$ 0.019$ & $\$ 0.020$ & $\$ 0.019$ & $\$ 0.010$ \\
\hline & $B$ & $\$ 0.013$ & $\$ 0.024$ & $\$ 0.022$ & $\$ 0.023$ & $\$ 0.025$ & $\$ 0.029$ \\
\hline & $C$ & $\$ 0.100$ & $\$ 0.592$ & $\$ 0.542$ & $\$ 0.526$ & $\$ 0.518$ & $\$ 1.056$ \\
\hline & $D$ & $\$ 0.050$ & $\$ 0.414$ & $\$ 0.377$ & $\$ 0.363$ & $\$ 0.345$ & $\$ 0.779$ \\
\hline & RO & $-\$ 0.005$ & $-\$ 0.005$ & $-\$ 0.005$ & $-\$ 0.005$ & $-\$ 0.005$ & $-\$ 0.009$ \\
\hline \multirow{5}{*}{$\begin{array}{c}\text { User } \\
\text { Pays, \$ }\end{array}$} & $A$ & $\$ \$ 884$ & $\$ 975$ & \$\$969 & $\begin{array}{l}368 \\
\end{array}$ & $1 \$ 973$ & $\$ \$ \$ 517$ \\
\hline & $B$ & $\$ 664$ & $\$ 0$ & $\$ 0$ & $\$ 0$ & $\$ 0$ & $\$ 0$ \\
\hline & $C$ & $-\$ 100$ & $-\$ 592$ & $-\$ 542$ & $-\$ 526$ & $-\$ 518$ & $-\$ 1,056$ \\
\hline & $D$ & $\$ 26$ & $-\$ 414$ & $-\$ 377$ & $-\$ 363$ & $-\$ 345$ & $-\$ 779$ \\
\hline & $\mathrm{RO}$ & $-\$ 588$ & $-\$ 662$ & $-\$ 962$ & $-\$ 895$ & $-\$ 874$ & $-\$ 1,865$ \\
\hline
\end{tabular}

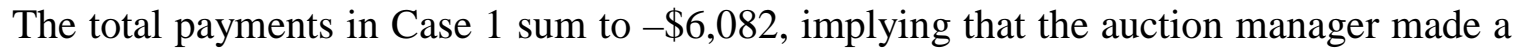
net payment to users and the RO to ensure that the control points were satisfied. Note also that users $c$ and $d$ sold nearly all their water, and at a high price. Net payment to the RO was $\$ 5,847$, for 1,096,295 $\mathrm{m}^{3}$ of water over all 8 periods, an average payment of $\$ 0.00555 / \mathrm{m}^{3}$.

At this point, each farmer would have firm rights to the allocated water for the first period, and provisional rights to water in the remaining periods. Similarly, the RO would be obligated to release $117,578 \mathrm{~m}^{3}$ in the first period, and would have a provisional obligation to release the water as scheduled in remaining periods. In the next period's auction, the provisional quantities would become initial rights or obligations, and payments would be calculated on that basis. The auction manager may wish to scale all users' rights (including the RO's) in order to guarantee a revenue-neutral auction. 


\section{Case 2. RO Restricts Releases.}

Case 2 examines the effect on groundwater users when the RO raises prices by simply restricting releases. The RO bids the same prices as before, but cuts each quantity in half. The objective value was $\$ 27,041$, which is less than objective value in Case 1 . Again, the only binding control point constraints were associated with Control Points 3 and 4 . The full solution for Case 2 is shown in Table 2

The RO releases a total of 584,789 $\mathrm{m}^{3}$ over the 8 periods (including 25,000 in each of periods 7 and 8 , not shown in the table), and receives a total payment of $\$ 4,043$, less than before, but for an average price of $\$ 0.00860 / \mathrm{m}^{3}$, much higher than in Case 1 . Interestingly, mainly farmer $A$ is affected, and surprisingly, farmer $D$ actually takes a little more in period 1 . Prices for the farmers do not uniformly rise, and where they do increase, they change by only a little. Hence, the groundwater has buffered the reduction in release from the RO. Hence, even for a simple example, the groundwater and surface water interactions are complicated, and may have counter-intuitive results.

Table 2. Solution to Case 2 with $\mathrm{RO}$ reducing releases. The $\mathrm{RO}$ also releases 25,000 $\mathrm{m}^{3}$ in periods 7 and 8 .

\begin{tabular}{|c|c|c|c|c|c|c|c|}
\hline & User & Period 1 & Period 2 & Period 3 & Period 4 & Period 5 & Period 6 \\
\hline \multirow{5}{*}{$\begin{array}{l}\text { Quantity, } \\
\mathrm{m}^{3}\end{array}$} & $A$ & 98,789 & 68,475 & 62,426 & 50,000 & 88,043 & 100,000 \\
\hline & $B$ & 100,000 & 50,000 & 50,000 & 50,000 & 50,000 & 31,722 \\
\hline & $C$ & 0 & 0 & 0 & 0 & 0 & 0 \\
\hline & $D$ & 1,526 & 0 & 0 & 0 & 0 & 0 \\
\hline & $\mathrm{RO}$ & 116,893 & 92,497 & 100,000 & 77,826 & 97,574 & 100,000 \\
\hline \multirow{5}{*}{ Price, \$ } & $A$ & $\$ 0.020$ & $\$ 0.020$ & $\$ 0.020$ & $\$ 0.020$ & $\$ 0.020$ & $\$ 0.011$ \\
\hline & $B$ & $\$ 0.016$ & $\$ 0.023$ & $\$ 0.024$ & $\$ 0.022$ & $\$ 0.026$ & $\$ 0.030$ \\
\hline & $C$ & $\$ 0.094$ & $\$ 0.511$ & $\$ 0.613$ & $\$ 0.517$ & $\$ 0.502$ & $\$ 0.050$ \\
\hline & $D$ & $\$ 0.050$ & $\$ 0.352$ & $\$ 0.430$ & $\$ 0.357$ & $\$ 0.332$ & $\$ 0.813$ \\
\hline & $\mathrm{RO}$ & $-\$ 0.010$ & $-\$ 0.005$ & $-\$ 0.006$ & $-\$ 0.005$ & $-\$ 0.005$ & $-\$ 0.010$ \\
\hline \multirow{5}{*}{$\begin{array}{c}\text { User } \\
\text { Pays, \$ }\end{array}$} & $A$ & $\$ 976$ & $\$ 370$ & $\$ 249$ & $\$ 0$ & $\$ 761$ & $\$ 540$ \\
\hline & $B$ & $\$ 779$ & $\$ 0$ & $\$ 0$ & $\$ 0$ & $\$ 0$ & $-\$ 548$ \\
\hline & $C$ & $-\$ 94$ & $-\$ 511$ & $-\$ 613$ & $-\$ 517$ & $-\$ 502$ & $-\$ 50$ \\
\hline & $D$ & $\$ 26$ & $-\$ 352$ & $-\$ 430$ & $-\$ 357$ & $-\$ 332$ & $-\$ 813$ \\
\hline & $\mathrm{RO}$ & $-\$ 1,169$ & $-\$ 462$ & $-\$ 560$ & $-\$ 389$ & $-\$ 488$ & $-\$ 974$ \\
\hline
\end{tabular}

\section{Future work}

The example and model are highly simplified. A real market would have many more time periods, and the value of water in the last period would be a critical value driving earlier allocations and prices. Furthermore, a hydrogenerator is likely to have a chain of reservoirs on a given river, and the preferred approach is stochastic optimization. The key contribution here is 
the conceptual approach for trading between a hydrogenerator and irrigators, taking into account the surface water and ground water interactions.

\section{References}

Ahlfeld, D. P., P. M. Barlow, and E.E. Mulligan. (2005). GWM - A ground-water management process for the U.S. Geological Survey modular ground-water model (MODFLOW 2000). U.S. Geological Survey Open-File Report 2005-1072.

Bjornlund, H. (2003). "Efficient Water Market Mechanisms to Cope with Water Scarcity." Water Resources Development, 19(4), pp. 553.

Cai, X., M. W. Rosegrant, C. Ringler (2003). "Physical and economic efficiency of water use in the river basin: Implications for efficient water management." Water Resources Research, 39(1), pp. 1-12.

Greenwald, R. (1998). "MODMAN: An optimization module for MODFLOW Version 4.0."

Griffin, R. C. and G. W. Characklis (2002). "Issues and Trends in Texas Water Marketing." Water Resources Update, 121, pp. 29-33.

Pulido-Velazquez, M., J. Andreu, A. Sahuquillo (2006). "Economic Optimization of Conjunctive Use of Surface Water and Groundwater at the Basin Scale." Journal of Water Resources Planning and Management, 132(6), pp. 454-467.

Raffensperger, J.F., and M.W. Milke (2005). “A Design for a Fresh Water Spot Market.” Water and Science Technology: Water Supply, 5(6), pp. 217-224.

Raffensperger, J.F., M.W. Milke and E.G. Read (2009). “A Deterministic Smart Market Model for Ground Water” Operations Research. 